\title{
Ectophosphodiesterase/nucleotide phosphohydrolase (Enpp) nucleotidases: cloning, conservation and developmental restriction
}

\author{
KARINE MASSÉ ${ }^{1, \#, ~ S U R I N D E R ~ B H A M R A ~}{ }^{1}$, GAVIN ALLSOP ${ }^{2}$, NICHOLAS DALE$^{1}$ and ELIZABETH A. JONES ${ }^{*}, 1$ \\ ${ }^{1}$ Department of Biological Sciences, Warwick University, Coventry and \\ ${ }^{2}$ Faculty of Biological Sciences, Institute of Molecular and Cellular Biology, Leeds University, U.K.
}

\begin{abstract}
Ectonucleotidase proteins occupy a central role in purine signalling regulation by sequentially hydrolysing ATP to ADP and to adenosine. The ENPP (or PDNP) gene family, which encodes ectophosphodiesterase/nucleotide phosphohydrolases, is a subfamily of these enzymes, which consists of 7 members in mammals. These proteins catalyse the generation of bioactive lipids, placing the ENPP enzymes as key regulators of major physiological signalling pathways and also important players in several pathological conditions. Here we report the cloning of all the members, except enpp5, of the enpp family in Xenopus laevis and tropicalis. Phylogenetic analyses demonstrate the high level of conservation of these proteins between amphibian and other vertebrate species. During development and in the adult frog, each gene displays a distinct specific expression pattern, suggesting potentially different functions for these proteins during amphibian embryogenesis. This is the first complete developmental analysis of gene expression of this gene family in vertebrates.
\end{abstract}

KEY WORDS: ectonucleotidase, ectophosphodiesterase/nucleotide phosphohydrolases, purine metabolism, bioactive lipid metabolism, Xenopus laevis, embryogenesis, gene expression

\section{Introduction}

Ecto-nucleotide pyrophosphates/phosphodiesterases (ENPP) form a group of widely and phylogenetically conserved proteins, from bacteria to plants. These enzymes, belonging to the superfamily of ectonucleotidases, catalytically interact with a wide range of nucleotides (purines and pyrimidines) and their derivatives (Zimmermann, 1999, 2001) They are able to hydrolyse the pyrophosphate and phosphodiester bonds of their substrates to nucleoside 5'monophosphates. ENPP2 displays a wider catalytic capacity by being able to hydrolyse AMP to adenosine. The ENPP family is, therefore, involved in the generation, breakdown and recycling of extracellular nucleotides (reviewed in Bollen et al., 2000; Stefan et al., 2006) and also in modulation of the nucleoside tri/diphosphates, known as P2 purinergic, receptor-mediated signalling (Grobben et al., 2000; Lazarowski et al., 2000). The recent discovery that ENPP2 is identical to lysophospholipase D (lysoPLD), which hydrolyses lysophosphatidylcholine (LPC) into lysophosphatidic acid (LPA; mono-acylglycerol-3-phosphate) or sphingosylphosphorylcholine (SPC) to sphingosine-1 phosphate (S1P) has widened the potential physiological functions of these enzymes (Tokomura et al., 2002; Umezu-Goto et al., 2002).

To date, seven members have been cloned in mammals and are numbered according to their order of discovery (reviewed in Zimmermann, 2001; Goding et al., 2003; Stefan et al., 2005). ENPP1 was initially discovered as a membrane glycoprotein on plasma cells, as Plasma-Cell differentiation antigen-1 or PC-1 (Takahashi et al., 1970; Rebbe et al., 1991). ENPP2 $\alpha$ or autotaxin was first identified as a potent mobility-stimulating glycoprotein secreted by the human melanoma cell line A2058 (Stracke et al., 1992; Murata et al., 1994). Several splice variants have now been described, such as ENPP2 $\beta$ (PD-l $\alpha$ ), which lacks 52 amino acids Abbreviations used in this paper: Enpp, ectophosphodiesterase/nucleotide
phosphohydrolases.

\footnotetext{
*Address correspondence to: Elizabeth A. Jones. Department of Biological Sciences, Warwick University, Coventry, CV4 7AL, U.K. Fax: +44-24-7652-3701. e-mail: elizabeth.Jones@warwick.ac.uk \#Current Address: Université Bordeaux, UMR-CNRS 5164, 33076 Bordeaux Cedex, France.
}

Supplementary Material for this paper (figure and tables) is available at: http://dx.doi.org/10.1387/ijdb.092879km

Accepted: 6 February 2009. Final author-corrected PDF published online: 3 July 2009. Edited by: Roberto Mayor.

ISSN: Online 1696-3547, Print 0214-6282

(1) 2009 UBC Press

Printed in Spain 
in the central domain of the protein and ENPP2 $\gamma$ which contains an additional region of 25 residues (Narita et al., 1994; Kawagoe et al., 1995). ENPP3 was first described as gp130 RB13-6 a glycoprotein recognised by antibody RB13-6 but it is also known as B10, PD-1 $\beta$ or more recently as the antigen recognised by the monoclonal antibody 97A6 (Deissler et al., 1995; Scott et al., 1997; Jin-Hua et al., 1997; Bühring et al., 2001). These three family members display a very similar primary structure, with a short intracellular $\mathrm{N}$ terminal region, a type II transmembrane domain and a large extracellular C-terminal domain. The latter consists of two somatomedin-B-like domains, involved in potential protein interactions, a catalytic domain with the conserved catalytic T210 and a nuclease-like domain with a putative "EF-hand" calcium binding motif (reviewed in Bollen et al., 2000). The "EF-hand" has been shown to be essential for ENPP1 and ENPP3 enzymatic activity (Andoh et al., 1999) however deletion of this motif has little or no effect on ENPP2 activity and properties (Lee et al., 2001). The single catalytic site mediating both nucleotide pyrophosphatase and phosphodiesterase activities (Gijsbers et al., 2001) is essential for the hydrolysis of lysophospholipids (Gijsbers et al., 2003). Moreover, a single mutation in the mouse Enpp2 catalytic site leads to an inactive enzyme. Homozygous knock out mice bearing this mutation die at an early stage of development, suggesting that enzymatic activity of Enpp2 is critical to normal development (Ferry et al., 2007). However, domain-swapping experiments recently demonstrated that the lysophospholipase D activity of ENPP2 depends also on the N-terminal and C-terminal "nuclease like" domains (Cimpean et al., 2004). ENPP1 and 3 are ecto-enzymes whereas ENPP2 has now been shown to be synthesized as a prepro-enzyme and secreted (Jansen et al., 2005). ENPP4-7 are shorter proteins with a smaller catalytic extracellular domain and a type I transmembrane domain in their $\mathrm{C}$ terminus. However, truncated forms of ENPP6 and 7 can be secreted (Wu et al., 2004; Sakagami et al., 2005). ENPP4 and ENPP5 have been described as putative ENPP ectoenzymes based on their sequence homology with the previously identified members of the family (Gijsbers et al., 2001). However, little is known about their catalytic activity. ENPP6 is a choline-specific glycerophosphodiesterase, with lysophospholipase $\mathrm{C}$ activity towards lysophosphatidylcholine (LPC) (Sakagami et al., 2005) ENPP7 is better known as alkaline sphingomyelinase (alk-SMase) with no detectable nucleotidase activity (Duan et al., 2003).

Human ENPP1-5 proteins have been detected in many organs (Bollen et al., 2000) and despite their wide distribution, specific functions have been attributed to each member (reviewed in Goding et al., 2003). ENPP1, by producing pyrophosphate (PPi) from extracellular nucleotides, plays a central role in the regulation of calcification (reviewed in Terkeltaub, 2006). Tip-toe walking mice (Ttw), characterised by an ossification of the spinal ligaments and model of the human ossification of the posterior longitudinal ligament (OPLL), have a nonsense mutation in the Enpp1 gene (Okawa et al., 1998). Mutations in human ENPP1 cause several pathological calcification syndromes, such as Idiopathic Infantile Arterial Calcification (IIAC) (Rutsch et al., 2003) and Ossification of the Posterior Longitudinal Ligament of the spine (OPLL), a cause of myelopathy in Japan and Southeast Asia (Nakamura et al., 1999). ENPP1 has also been shown to directly interact with the insulin receptor (Maddux and Goldfine, 2000) and several studies have shown a correlation of the $\mathrm{K} 121 \mathrm{Q}$ polymorphism with in- crease of insulin resistance in diabetes although the exact role of ENPP1 in insulin signalling remains controversial (see Goding et al., 2003). However, a recent study demonstrates the genetic link between ENPP1 gene variants and childhood and adult obesity and type-2 diabetes (Meyre et al., 2005). ENPP3, which is specifically expressed in basophils and mast cells (Bühring et al., 1999) may be a marker for allergy diagnosis (Bühring et al., 2004). ENPP2, due to its ability to generate LPA, is involved in cell survival, proliferation and tumor cell motility (reviewed in Stefan et al., 2005; van Meeteren and Moolenaar, 2007). Creation of Enpp2 mutant mice revealed the importance of this protein for embryonic vasculature (Tanaka et al., 2006; van Meeteren et al., 2006) and it has been suggested that ENPP2 might play an important role during neurogenesis, since its transcripts are first detected in the developing nervous system in chick and mouse embryos (Bächner et al., 1999; Ohuchi et al., 2007). However, homozygous mutants are embryonic lethal at mid-gestation (E9.5-E10.5), preventing any further analysis. Human and mouse ENPP6 are predominantly found expressed in the kidney and might be involved in resorption of choline by degrading choline-containing compounds (Sakagami et al., 2005). ENPP7, specifically expressed in the intestine, is involved in the digestion of dietary sphingomyelin (SM) and may have a colonic anti-cancer activity (reviewed in Duan, 2006)

Although intensive work has demonstrated the physiological roles of ENPP in adults, little is known about the roles of the ENPP proteins during development. Using Xenopus laevis as a vertebrate model, we have analysed the expression pattern of each member of this family. We report the cloning and characterisation of 6 members of the enpp family in $X$. laevis and $X$. tropicalis. We compare their temporal and spatial expression during development and also their distribution in adult frog tissues. Their developmentally restricted and dynamic distributions strongly suggest that this family of proteins play important developmental roles and that these roles would be specific for each enpp member.

\section{Results}

\section{Cloning of the different enpp genes}

All the members of the enpp family, except enpp5, were cloned using different strategies (Supplementary Table 1A). TBLASTN search of the $X$. laevis and tropicalis EST databases on the NCBI website allowed the identification of full length IMAGE clones or EST Unigenes coding for enpp2, enpp4, enpp6 and enpp7 (Accession numbers given in Supplementary Table 1B). When necessary, alignments of these sequences were performed to generate the consensus sequence of the cDNA. BLAST search on ESTs databases only allowed the cloning of partial sequences for Xenopus enpp1 and enpp3 cDNAs. The remaining sequences were identified by BLAST on the genomic $X$. tropicalis databases (JGI website) and the deduced cDNA sequences corrected by reference to the human sequence according to the Breathnach and Chambon law (Breathnach and Chambon, 1981). When needed, RT-PCRs were performed on $X$. laevis and tropicalis embryonic and adult tissues to amplify the missing sequences.

\section{Protein and phylogenetic analysis of the enpp family}

Consensus protein sequence deduced from conceptual translation of the cDNA sequences are given in Figs. 1 and 2 and each Xenopus enpp protein displays the characteristics features of this 

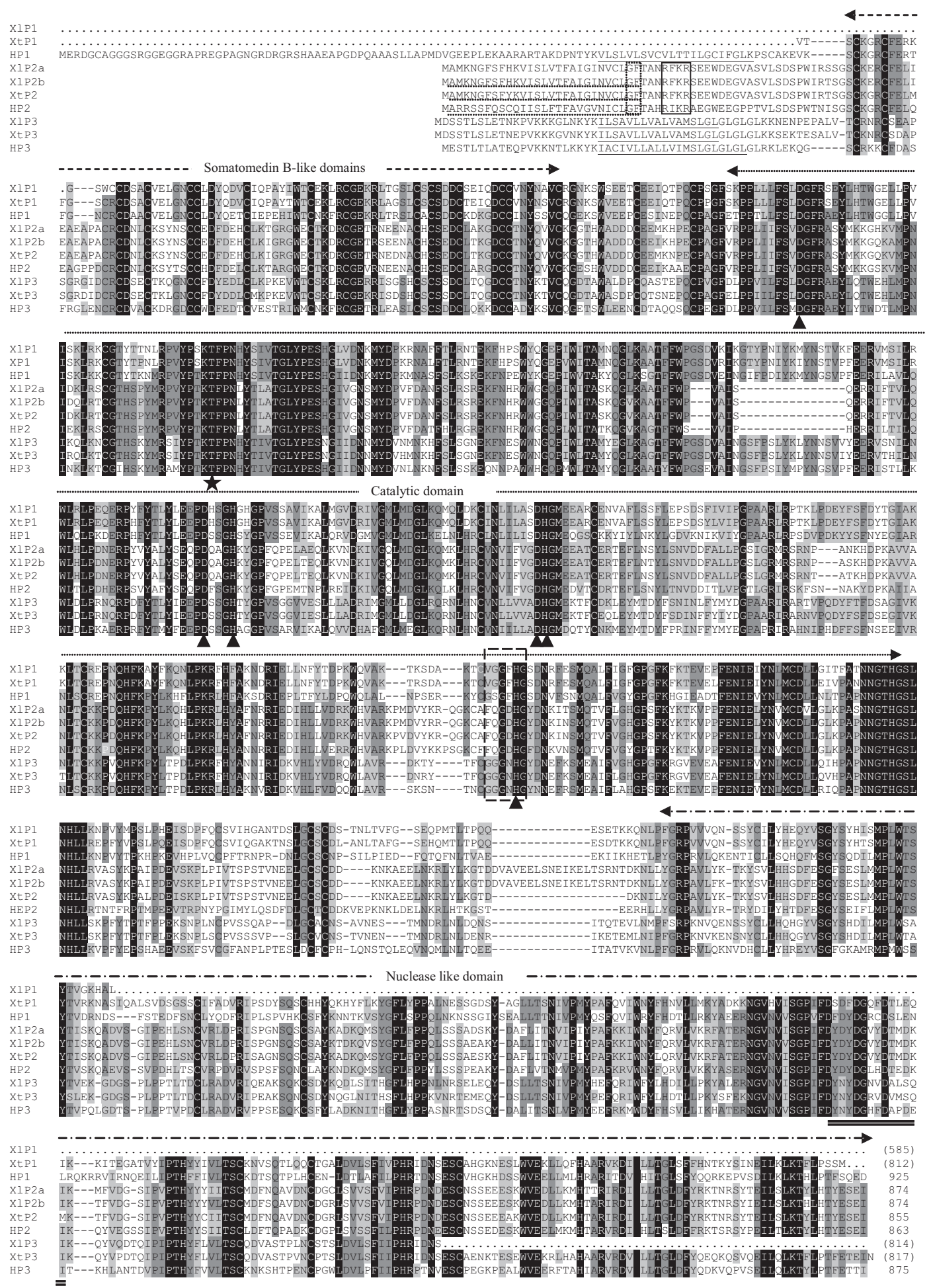

Fig. 1. Alignment of Xenopus enpp1, enpp2 and enpp3 proteins. The X. laevis (XI) and X. tropicalis (Xt) proteins were aligned with their human orthologs (H) using CLUSTALW. Residues conserved in all sequences are indicated by a black background. Residues conserved in two orthologous groups of enpp are indicated by a dark grey background. Similar or identical residues in at least 5 sequences are indicated by a light grey background. Missing sequences are indicated by dots. The different functional domains are indicated by the dashed and dotted arrows. The underlined sequences indicate the type 2 transmembrane domain in the $N$ terminal region. In enpp2 sequences, the dotted underlined sequences indicate the signal peptide, the signal peptide cleavage site is marked by the dotted box and the consensus site for recognition by furin is marked by the black box. The GXGXXG motif, dinucleotide binding residues, is indicated by a dashed box. The double underlined sequences represent the EF hand motif. $\star$ : Threonine catalytic-site; $\mathbf{\Lambda}$ : Putative metal binding residues. The Genbank accession numbers of the human ENPP proteins are given in the legend of Fig 3. The size of the proteins (AA numbers), complete or incomplete (in bracket) is also given. 
enzyme family. The $\mathrm{N}$-terminal sequences (corresponding to the cytoplasmic tail and transmembrane domain) are missing from the $X$. laevis and tropicalis enpp1 proteins (Fig. 1). The $\mathrm{C}$-terminal 60 amino acids are missing from $X$.laevis enpp3 sequence (Fig. 1 ). The $X$. laevis deduced enpp7 sequence is also incomplete, with the $\mathrm{N}$-terminal 20 amino acids missing from our sequence (Fig. 2). X. tropicalis enpp7 sequences obtained by EST and genomic sequences analysis are identical following translation except in their $\mathrm{C}$ terminal domain; however the sequence derived from JGI genomic sequence is incomplete. The enpp3 sequence obtained by conceptual translation of the $X$. tropicalis genomic sequence differs in the $\mathrm{C}$-terminus with our sequence based on EST analysis and is less conserved with the mammalian orthologs. Therefore, it is likely that our sequence provides the correct sequence for $X$. tropicalis enpp3 (Fig. 1).

A phylogenetic analysis of these enzymes in Xenopus and

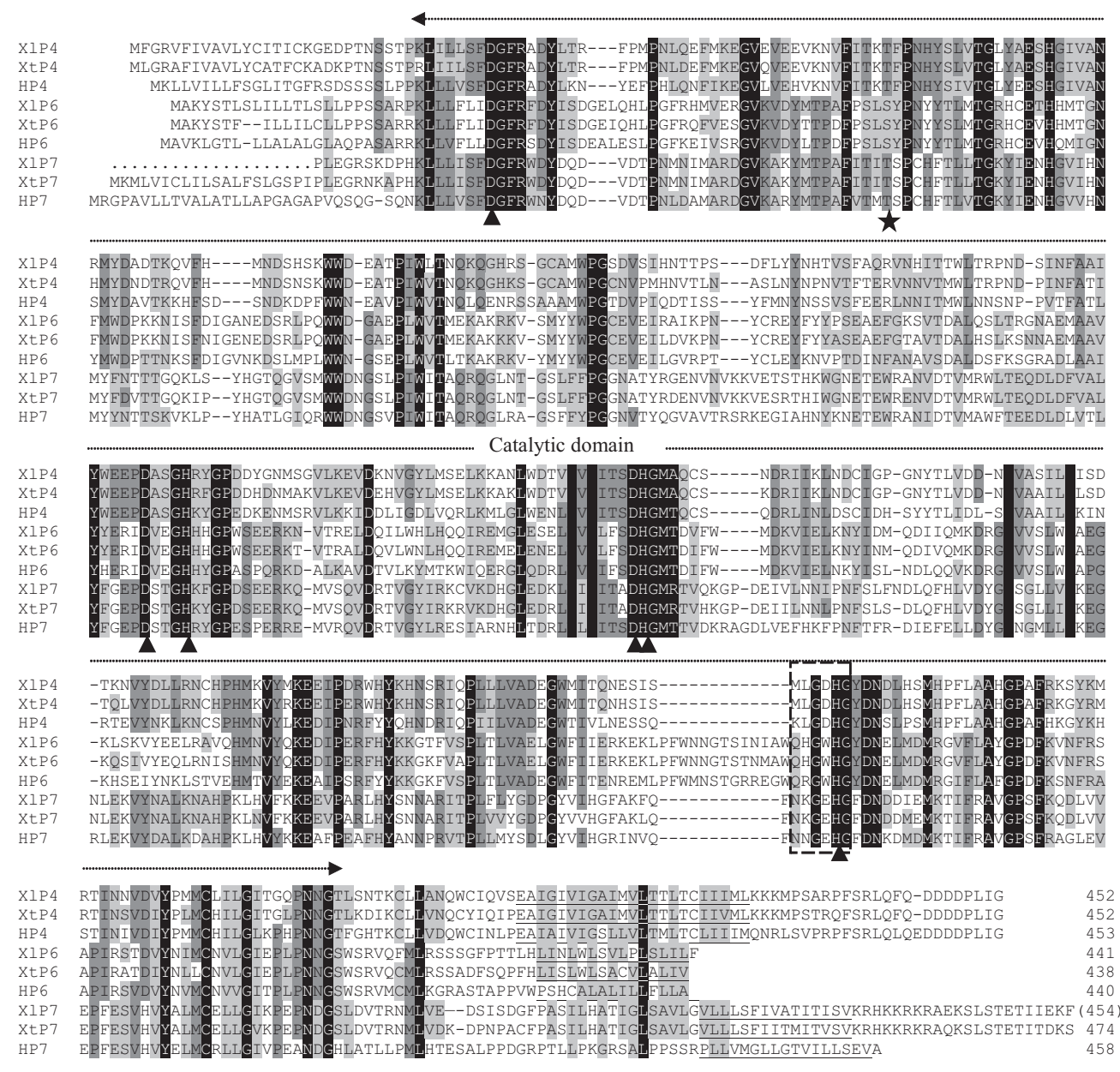

Fig. 2. Alignment of Xenopus enpp4, enpp6 and enpp7 proteins. The $X$. laevis $(X I)$ and $X$. tropicalis $(X t)$ proteins were aligned with their human orthologs (H) using CLUSTALW. Residues conserved in all sequences are indicated by a black background. Residues conserved in two orthologous groups of enpp sequences are indicated by a dark grey background. Identical or similar residues in at least 4 sequences are indicated by a light grey background. Missing sequences are indicated by dots. The dotted arrow indicates the catalytic domain. The underlined sequences indicate the type 1 transmembrane domain in the $C$ terminal region. The GXGXXG motif, dinucleotide binding residues, is indicated by a dashed box. $\star$ : Catalytic-site residue (T or S); $\mathbf{\Lambda}$ : Putative metal binding residues. The Genbank accession numbers of the human ENPP proteins are given in the legend of figure 3. The size of the proteins (AA numbers), complete or incomplete (in bracket) is also given. other vertebrates was carried out using the catalytic domains sequence of each protein. This analysis demonstrates the clear identity between the catalytic domains of orthologous proteins is more than $60 \%$, with enpp4 being the least conserved protein and enpp2 the most conserved member during vertebrate evolution (Table 1A). However, the percentage of identity between the catalytic domain of any Xenopus enpp1-3 and any Xenopus enpp 4-7 is only of $30 \%$ (Table 1B). As shown in Fig. 1, enpp1-3 proteins have a high percentage of identity over each different domain. For example, $X$. tropicalis enpp1 and enpp2 share $50.1 \%, 45.9 \%$ and $49.4 \%$ identity along their catalytic, nuclease-like and Somatomedin Blike domains respectively. The catalytic domain is the most conserved domain and Xenopus enpp1-3 share about $50 \%$ identity and more than $65 \%$ similarity with each other (Table 1B). A transmembrane type 2 domain is present in Xenopus enpp3 sequences at a similar position to that in human ENPP3, such a transmembrane domain could not be detected in Xenopus enpp1 proteins due to incomplete $\mathrm{N}$-terminal sequences.

We have identified two distinct genes coding for enpp2 in X.laevis (Fig. 1, Supplementary Fig. 1). These $2 X$. laevis proteins are $95.8 \%$ identical with 37 amino acid differences along their length (Supplementary Fig. 1). The 3 amphibian enpp2 proteins display the same features, characteristic of the enpp family, and the nucleotide binding sequence, GXGXXG, is replaced by $F X G X X G$ as in the other vertebrate ENPP2 proteins (Supplementary Fig. 1). Surprisingly, this sequence is also not conserved in $\mathrm{Xe}$ nopus enpp1, suggesting that these amphibian proteins might display different enzymatic properties to their mammalian orthologs. The $\mathrm{N}$ terminal domain is less conserved between Xenopus and the other vertebrate proteins. However, as in the case of human ENPP2, the Signal-P-Program predicts that this region can act as a cleavable signal peptide with the cleavage site located between F28 and T29. Moreover, the consensus cleavage site $R X K / R R$ for the endoprotease furin is present in all three frog enpp2 proteins (Fig. 1, 


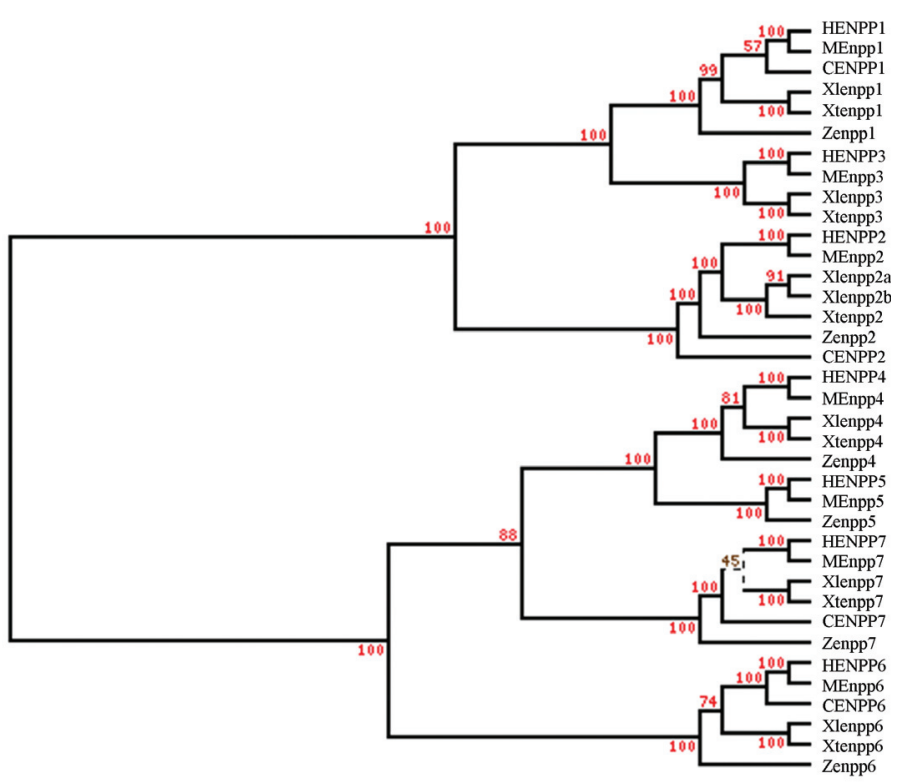

Supplementary Fig. 1). Furthermore, we have evidence that both $X$. laevis enpp2 are secreted proteins (data not shown). Therefore we named this new gene enpp2b as opposed to enpp2a (the previously described enpp2 on the NCBI database). Both enpp2a and enpp $2 b$ align with the same $X$. tropicalis genomic sequences (scaffold 330) and share similar percentage of identity to other vertebrate ENPP2 proteins (Table 1A).

Both Xenopus enpp4, 6 and 7 are highly similar but are less conserved compared to enpp1-3 during evolution (Table 1A,B). Even though each member shares more than $50 \%$ identity with its orthologs, the percentage of identity between their catalytic domains is only $30 \%$ in Xenopus (Table 1A). However, their sequence analysis predicted a primary structure similar to their mammalian orthologs (Fig. 2): one transmembrane domain located at the $\mathrm{C}$-terminal domain of the proteins and one $\mathrm{N}$-terminal signal peptide with a cleavage site between residues AA19-20 for both enpp4, between AA 22-23 for X.laevis enpp6 and AA 20-21 for X.tropicalis enpp6 and between residues AA 19-20 for $X$.tropicalis enpp7 (this domain could not be identified in $X$. laevis
Fig. 3. Phylogenetic conservation of the catalytic domains of ENPP proteins. A phylogenetic tree was constructed using the PHYLIP program. A cluster algorithm was used to build the tree. Bootstrap values are indicated at each node of the tree. The Genbank accession numbers of the ENPP proteins are as follows: human ENPP1: AAH59375; human ENPP2: AAH34961; human ENPP3: 014638; human ENPP4: EAX04292; human ENPP5: Q9UJA9; human ENPP6: NP_699174; human ENPP7: EAW89566; mouse Enpp1: NP_032839; mouse Enpp2: NP_056559; mouse Enpp3: NP_598766; mouse Enpp4: NP_950181; mouse Enpp5: Q9EQG7; mouse Enpp6: AAH96376; mouse Enpp7: NP_001025462; Chick ENPP1: XP_424539; chick ENPP2: XP_418466; chick ENPP6: XP_420512; chick ENPP7: XP_423912; zebrafish enpp1: CAl11601; zebrafish enpp2: NP_956897; zebrafish enpp4: AAH93443; zebrafish enpp5: NP_001025347; zebrafish enpp6: Q5BKW7; zebrafish enpp7: $X P \_685968$. The chick ENPP4 protein was excluded since its sequence is incomplete. XI:X. laevis; Xt:X.tropicalis; H: human; M: mouse; C: Chick; Z: Zebrafish.

TABLE $1 \mathrm{~A}$

\section{RELATEDNESS BETWEEN THE X.LAEVIS (XL) AND X.TROPICALIS (XT) NENPP CATALYTIC DOMAINS AND THEIR VERTEBRATE ORTHOLOGS}

\begin{tabular}{|c|c|c|c|c|c|c|}
\hline & $\begin{array}{c}\text { X.laevis } \\
\text { (pseudo) }\end{array}$ & X.tropicalis & Human & Mouse & Chick & Zebrafish \\
\hline Xlenpp1 & & $95.8(97.9)$ & $68.5(82.7)$ & $66.9(81.6)$ & $71.1(84.3)$ & $62.2(77.4)$ \\
\hline Xtenpp1 & & & $68.8(82.7)$ & $67.5(81.9)$ & $71.1(84.3)$ & $62.5(77.2)$ \\
\hline Xlenpp2a & $95.9(98.6)$ & $96.7(98.4)$ & $82.0(91.0)$ & $80.4(90.7)$ & $72.1(79.3)$ & $74.0(86.9)$ \\
\hline Xlenpp2b & & $97.8(99.5)$ & $82.3(91.6)$ & $80.7(91.0)$ & $72.6(80.0)$ & $74.6(87.2)$ \\
\hline Xtenpp2 & & & $83.7(91.8)$ & $81.5(91.0)$ & $73.8(80.5)$ & $74.0(87.2)$ \\
\hline Xlenpp3 & & $93.7(98.2)$ & $72.6(86.8)$ & $70.8(84.5)$ & nd & nd \\
\hline Xtenpp3 & & & $72.6(86.8)$ & $71.1(84.7)$ & nd & nd \\
\hline Xlenpp4 & & $85.3(92.8)$ & $63.5(76.4)$ & $62.1(78.0)$ & nd & $59.6(76.2)$ \\
\hline Xtenpp4 & & & $62.1(77.2)$ & $62.6(78.8)$ & nd & $59.6(77.0)$ \\
\hline Xlenpp6 & & 88.2(93.7) & $67.0(80.4)$ & $67.0(80.1)$ & $68.6(84.0)$ & $63.1(74.9)$ \\
\hline Xtenpp6 & & & $66.8(80.4)$ & $66.5(79.8)$ & $67.5(83.2)$ & $63.9(76.7)$ \\
\hline Xlenpp7 & & 93.3(97.1) & $68.0(81.3)$ & $67.7(81.6)$ & $69.8(83.7)$ & $66.8(79.8)$ \\
\hline Xtenpp7 & & & $66.6(81.3)$ & $66.6(82.1)$ & $69.4(84.5)$ & $66.2(80.6)$ \\
\hline
\end{tabular}

The percentage of amino acid identity and similarity (in bracket) between the ENPP catalytic domains was determined by pairwise alignment using the Needleman-Wunsch global alignment on the EMBL-EBI website. The Genbank accession numbers are given in the legends of Figure 3. nd, not determined.

TABLE 1B

RELATEDNESS OF THE CATALYTIC DOMAIN OF THE X. LAEVIS (XL) AND $X$. TROPICALIS (XT) ENPP (P) PROTEINS

\begin{tabular}{|c|c|c|c|c|c|c|c|c|c|c|c|c|}
\hline & XI enpp1 & Xt enpp1 & $\mathrm{XI}$ enpp2a & $\mathrm{XI}$ enpp2b & Xt enpp2 & XI enpp3 & Xt enpp3 & XI enpp4 & Xt enpp4 & XI enpp6 & Xt enpp6 & XI enpp7 \\
\hline \multicolumn{13}{|l|}{$\mathrm{XIP1}$} \\
\hline XtP1 & $95.8(97.9)$ & & & & & & & & & & & \\
\hline XIP2a & $50.1(66.9)$ & $49.6(66.9)$ & & & & & & & & & & \\
\hline $\mathrm{XIP} 2 \mathrm{~b}$ & $49.6(66.1)$ & $49.1(66.1)$ & $95.9(98.6)$ & & & & & & & & & \\
\hline XtP2 & $50.1(66.4)$ & $49.6(66.4)$ & $96.7(98.4)$ & $97.8(99.5)$ & & & & & & & & \\
\hline XIP3 & $56(74.9)$ & $55.8(75.4)$ & $51.2(65.9)$ & 51.7 (65.9) & $51.4(66.1)$ & & & & & & & \\
\hline XtP3 & $56.9(74.4)$ & $57(74.7)$ & $52.1(66)$ & $52.6(66.2)$ & $52.3(66.5)$ & 93.5(97.9) & & & & & & \\
\hline XIP4 & $36.2(52.2)$ & $35.7(51.9)$ & $34.7(48.5)$ & 34.5 (49) & $34.9(49)$ & $35.8(58)$ & $36.2(56.8)$ & & & & & \\
\hline $\mathrm{XtP} 4$ & $36.1(50.4)$ & $35(50.4)$ & $35.3(49.1)$ & $35.1(49.4)$ & $34.1(48.6)$ & $34.7(55.6)$ & $34.4(54.9)$ & $85.3(92.8)$ & & & & \\
\hline XIP6 & $30.8(48.5)$ & $30.5(47.8)$ & $29.3(46.6)$ & $28.3(46.5)$ & $27.6(45.5)$ & $28.9(46.8)$ & $28.6(46.6)$ & $34.4(53.7)$ & $34.8(54.2)$ & & & \\
\hline XtP6 & $30.2(46.9)$ & $29.6(45)$ & $28.4(48.1)$ & $27.9(48.1)$ & $26.7(46.8)$ & $27.7(46.1)$ & $27.1(45.8)$ & $32.6(53.2)$ & $33.9(53.1)$ & $88(93.5)$ & & \\
\hline XIP7 & $31.3(46.5)$ & $30.6(46.2)$ & $31.1(45.8)$ & $31.4(46.3)$ & $31.2(45.2)$ & $32.2(50.3)$ & $31.8(50.3)$ & $35.3(54.3)$ & $35.2(54.5)$ & $32.4(51.8)$ & $29.6(51)$ & \\
\hline XtP7 & $31.2(47.5)$ & $30.9(47.3)$ & $30.1(44.7)$ & $30.4(44.5)$ & $30.9(44.6)$ & $32.1(50.1)$ & $31.7(49.9)$ & $35.2(55.9)$ & $35.2(56.2)$ & $32.8(53.1)$ & $30.8(51.5)$ & $93.4(97.1)$ \\
\hline
\end{tabular}

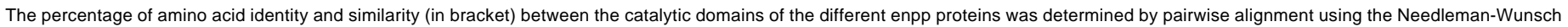
global alignment on the EMBL-EBI website. 
enpp7 due to incomplete $\mathrm{N}$-terminal sequences). Finally, the nucleotide binding sequence GXGXXG is not conserved in any of these proteins, suggesting that as their mammalian orthologs, these amphibian proteins might not be involved in the purinergic signalling pathway but hydrolyse bioactive lipids. Moreover, the catalytic $T$ residue is conserved in all sequences, and as in ENPP6 mammalian orthologs, is replaced by an $S$ in the frog enpp6 proteins.

\section{Spatial expression of the enpp gene family in the adult frog}

The distribution of enpp gene expression in the adult frog was analysed by RT-PCR (Fig. 4). enpp1 and enpp4 are ubiquitously expressed genes, as their transcripts can be detected in each organ tested. enpp3 also displays a wide expression pattern; however, the level of expression is higher in the intestinal tract, kidney, lung and eyes. enpp 6 is more expressed in ovary and kidney and no expression can be detected in the intestinal tract. enpp2a, enpp2b and enpp7 display a more restricted expression pattern. enpp7 is the most tissue specific gene as it is specifically highly expressed in the small intestine (duodenum and ileum). enpp7 is the only gene of the enpp family not to be expressed in the nervous system. The pseudo-alleles of enpp2 display a different expression profile: enpp2a expression can only be detected at low level in the nervous system and reproductive organs whereas enpp2b display a wider expression domain with a higher level of expression in the spinal cord, brain and ovary.

\section{Temporal expression of the enpp genes during $\mathrm{X}$. laevis development}

The temporal embryonic expression of these genes was assessed by RT-PCR (Fig. 5). All genes are expressed maternally except enpp7. enpp7 zygotic expression is only detected weakly at stage 41 but up-regulated by stage 45 , the last stage tested in this experiment, ruling out a role of this gene during early development. enpp1, enpp2b and enpp4 display a similar expression pattern. These genes are highly expressed at maternal stages. Their zygotic expression is weakly detected during gastrula (stage 10.5) but the level of expression increases until stage 45. Expression of enpp2a is more constant during development, with its level of expression being the lowest during gastrula. enpp3 is expressed maternally at low levels. The zygotic expression of enpp3 is strongly detected from stage 13 to stage 25 and then decreases from stages 27 to 37 , but remains expressed until stage 45. enpp6 is the highest maternally expressed member of the family. Its zygotic expression can be amplified after swimming tadpole stages; the weakly detected expression during gastrula and neurula stages may be as a consequence of non-degraded maternal transcripts.

\section{Spatial expression of the enpp gene family during develop- ment of $\mathrm{X}$. laevis}

The spatial expression of the enpp genes was detected by whole-mount in situ hybridisation (WISH). WISH was carried out on embryos from stage 5 to stage 45 , based on the temporal expression of each gene established by RT-PCR. Specific antisense probes were used to detect each gene and sense probes were used to control the specificity of the staining. In some cases, non-specific staining in the notochord was detected with the sense probes. As shown in Figs. 6 and 7, the expression of all enpp members can be detected throughout $X$. laevis development except enpp3. Moreover, enpp genes display distinct expression domains suggesting specific roles for each member
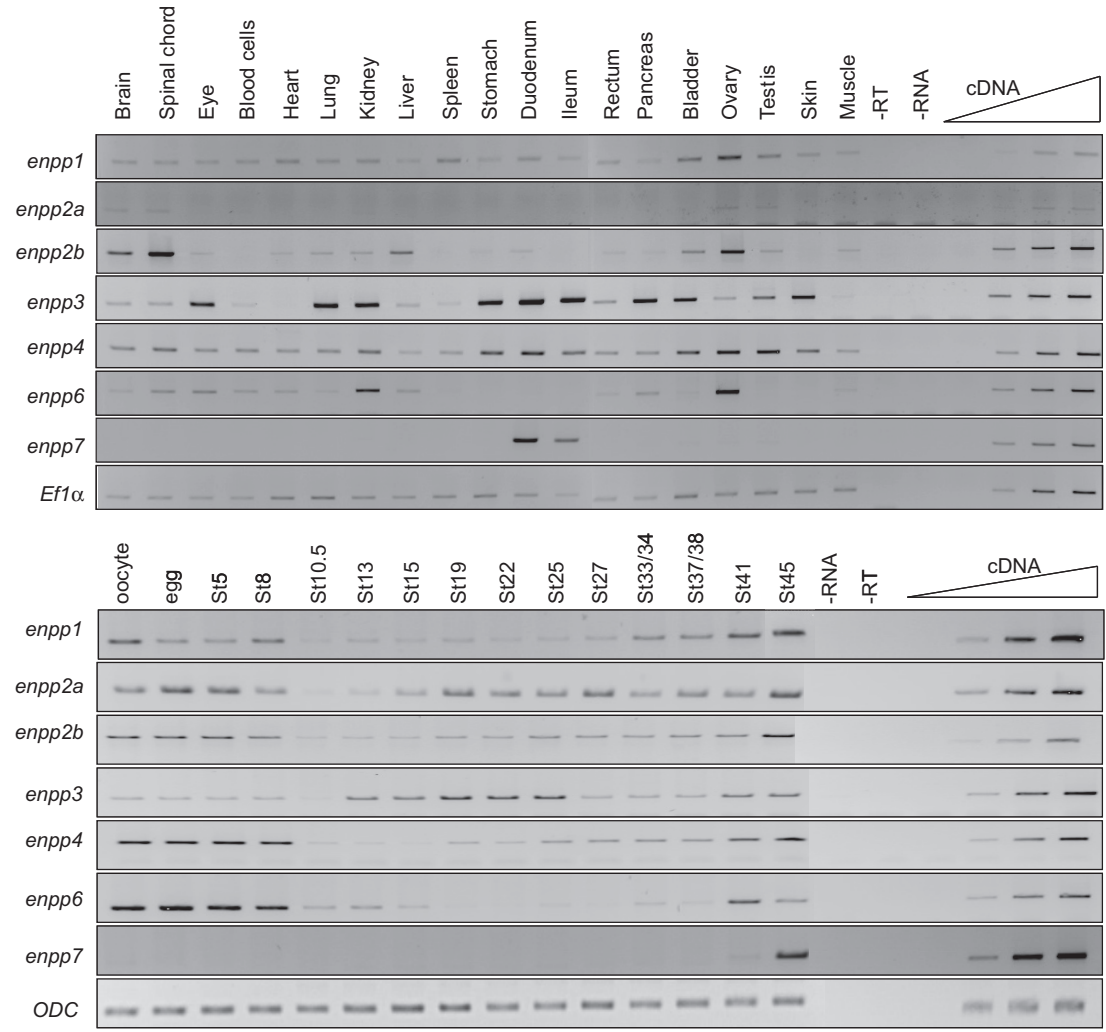

Fig. 4 (Left). Spatial expression profiles of enpp genes in the adult frog. $R T-P C R$ analysis showing the expression pattern of the enpp genes in X. laevis adult tissues. enpp1 and enpp4 are expressed in all tissues tested. enpp2b, enpp3 and enpp6 display a wide expression profile whereas enpp2a and enpp7 are more tissue specific. EF $1 \alpha$ was used as a loading control. The linearity was performed with doubling dilutions of CDNA from the following tissues: heart for enpp1, brain for enpp2a and enpp2b, skin for enpp3, ovary for enpp4, kidney for enpp6 and ileum for enpp7.

Fig. 5 (Left). Temporal expression profiles of enpp genes during embryogenesis. RT-PCR analysis showing the temporal expression profile of the enpp genes in $\mathrm{X}$. laevis unfertilised eggs and embryos. enpp1, enpp2a, enpp2b, enpp3 and enpp4 are expressed at almost all stages tested. The level of enpp6 expression is higher during maternal stages whereas enpp7 expression is only detected from stage 41. ODC was used as loading control.The linearity was performed with doubling dilutions of cDNA from stage 5 embryos for enpp2b, enpp4 and enpp6 and from stage 45 embryos for enpp1, enpp2a, enpp3 and enpp7. 
A


B
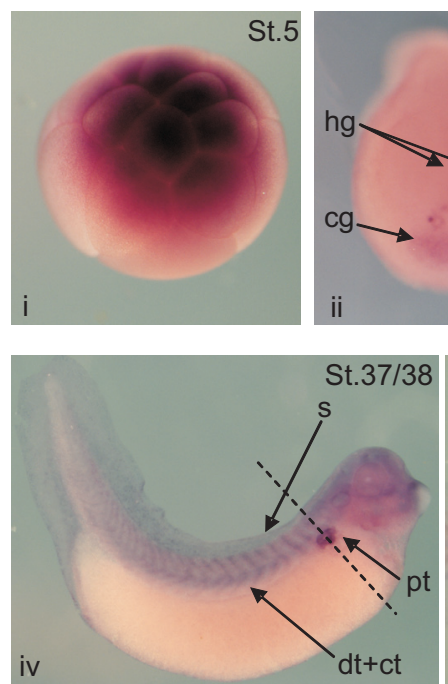

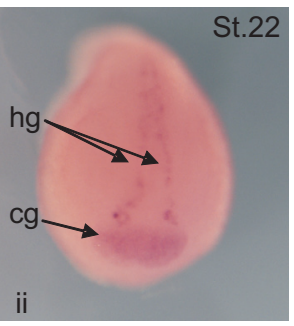

St.22



iii

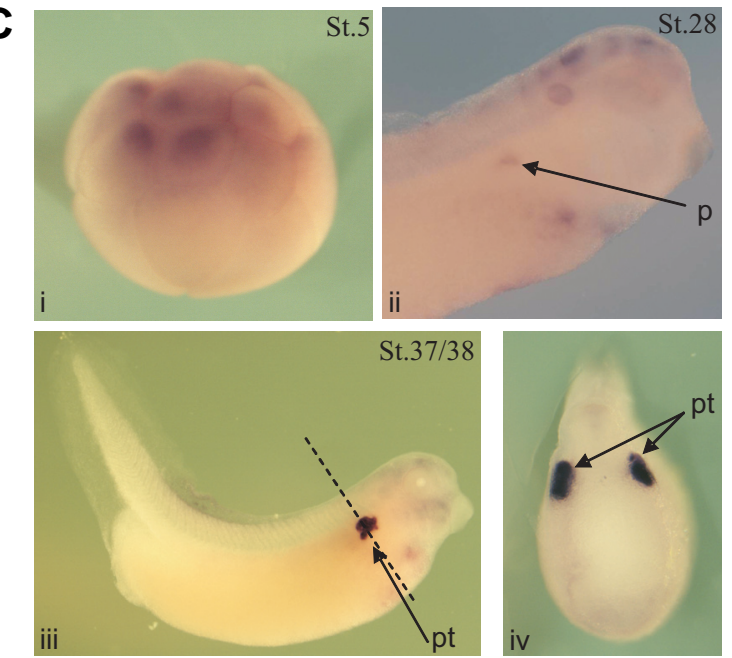

D

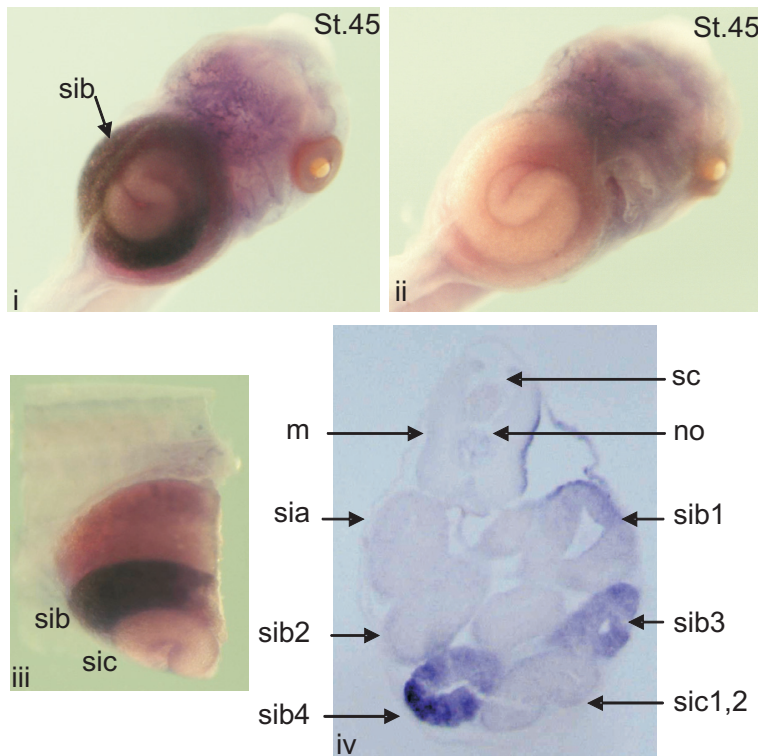

Fig. 6. Spatial expression profile of enpp1, 4, $\mathbf{6}$ and $\mathbf{7}$ during development. Whole mount in situ hybridisation with DIG-labelled antisense RNA probes was performed on embryos from stages 5-41 for enpp1, 4, 6 and stages 32-45 for enpp7. All embryos were analysed from the same experimental set. The differences in colours result from clearing the embryos and photographing them against a white background to visualise staining. (A) Whole-mount in situ hybridisation analysis of enpp1 expression. Lateral view at stages 28 (i), 35/36 (ii) and $37 / 38$ (iii). Detail of the fin at stage 41 (iv) and dorsal view of a stage 41 embryo (v). Anterior is right and dorsal is up, except in (v). da, dorsal aorta; dc, duct of cuvier; dlav, dorsal longitudinal anastomosing vessel; $h$, heart; pcv, posterior cardinal vein; ps, pronephric sinus; vbi, ventral blood island. (B) Whole-mount in situ hybridisation analysis of enpp4 expression. Animal view at stage 5 (i), anterior view at stage 22 (ii), lateral view at stages 32 (iii), $37 / 38$ (iv) and 41 (v). For the lateral views, dorsal is up and anterior is right. Transverse sections at stage 37/38 through the proximal tubules (vi). Dorsal is up. The dotted line through the pronephric tubules (iii) correspond to planes of section in (vi). cg: cement gland; ct, collecting tubules; dt, distal tubules; hg, hatching gland; pt, proximal tubules; s, somites. (C) Whole-mount in situ hybridisation analysis of enpp6 expression. Lateral view at stage 5 (i), lateral view at stage 28 (ii) and $37 /$ 38 (iii). Dorsal is up and anterior is right. Transverse sections in the proximal tubules level at 37/38 (iv). The dotted line through the pronephric tubules correspond to planes of section in (iv). p, pronephros; pt, proximal tubules. (D) Whole-mount in situ hybridisation analysis of enpp7 expression. Ventral view of stage 45 embryos hybridized with anti-sense (i) and sense (ii) probe, lateral view of the gut region of a stage 45 embryo (iii), cryostat section (iv) at $28 \mu \mathrm{m}$ of a stage 45 embryo through the gut. no, notochord; $m$, muscles; sc, spinal cord; sia, first sections of the small intestine; sib, external coil of small intestine; sic, internal coil of small intestine (from Chalmers and Slack, 1998).

\section{during $X$. laevis development.}

enpp1 maternal expression is detected in the animal pole of the embryo at stage 3 and 8 (data not shown). Zygotically, enpp1 is weakly detected at stage 28 in the ventral blood island (Fig. $6 \mathrm{Ai})$. At this stage, the staining observed in the notochord and otic vesicle may be non-specific since it is observed with the sense control probe (data not shown). At stage 35 , the staining in the blood compartment is more intense but no staining can be observed in the dorsal lateral plate, the other blood compartment (Fig. 6Aii). At later stages, enpp1 is still expressed in the ventral blood island and its transcripts can be detected in the vasculature of the embryo, such as the posterior cardinal vein, the dorsal aorta 
A

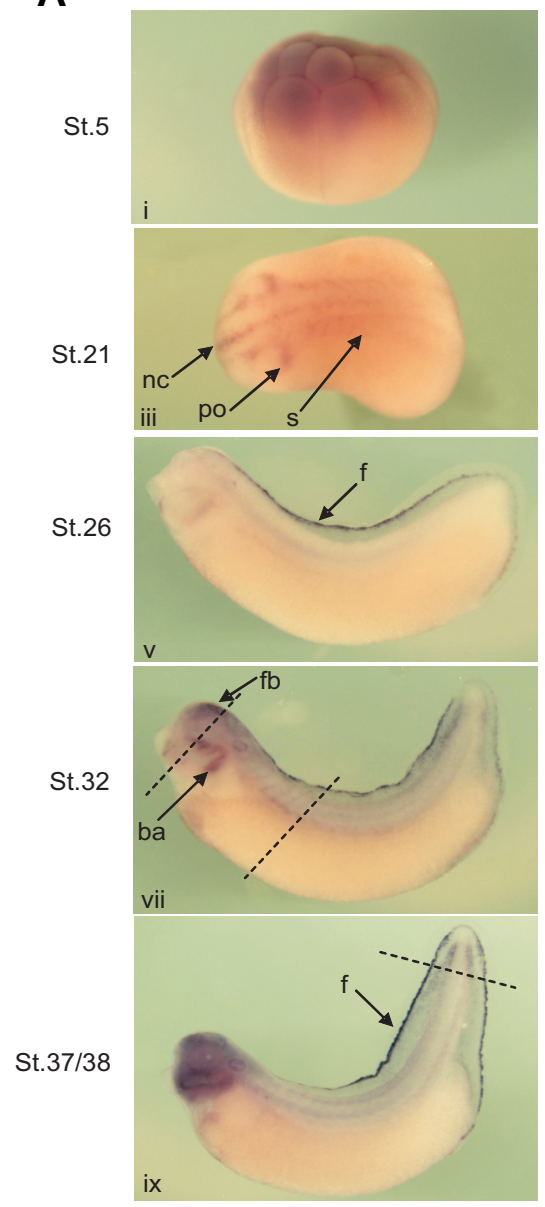

enpp2b
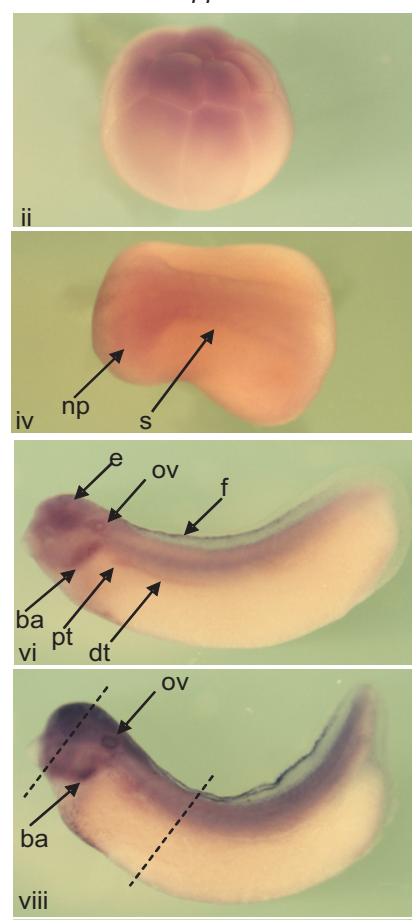

viii

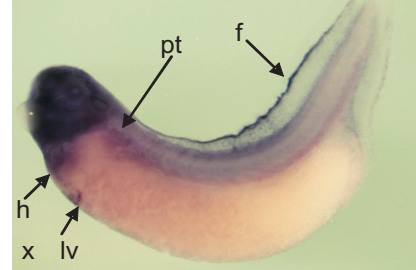

B
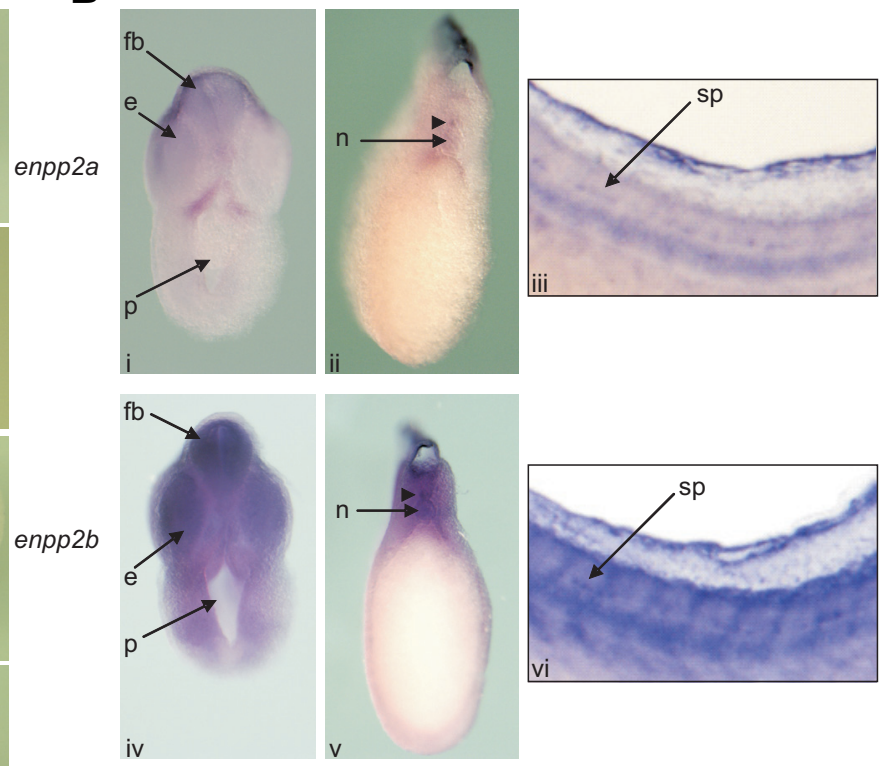

C
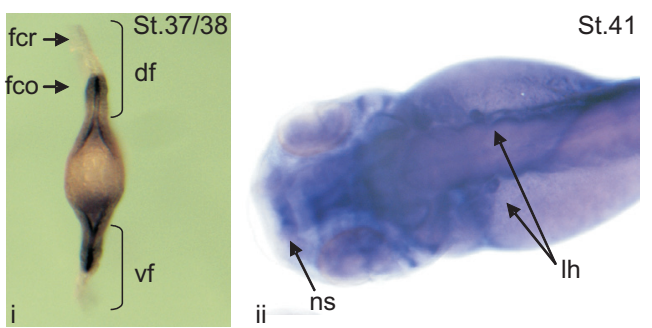

St.41

Fig. 7. Comparison of the spatial expression profile of enpp2a and enpp2b genes during development. (A) Whole-mount in situ hybridisation with an enpp2a and enpp2b DIG labelled anti-sense RNA probe was performed on embryos from stages 5-41. Animal view at stage 5 (i, ii). Lateral view at stage 21 (iii, iv), stage 26 ( $\mathrm{v}$, vi), stage 32 (vii, viii) and stage 37/38 (ix, x). Dorsal is up and anterior is left. The dotted line through the fins (ix) corresponds to plane of section in Ci. (B) Whole-mount in situ hybridisation with an enpp2a and enpp2b DIG labelled antisense RNA probe on stage 32 embryos. Transverse section through the head (i, iv) and trunk (ii, v) levels. Lateral view of the trunk region (iii, vi). Arrowheads indicate the staining in the spinal cord. (C) Whole-mount in situ hybridisation with an enpp2a DIG labelled antisense RNA probe. Transverse section through the fin at stage 37/38 (i). Dorsal view of a stage 41 cleared embryo (ii). ba, branchial arches; df, dorsal fin; dt, distal tubules; e, eye; f, fin; fb, forebrain; fcr, fin crest; $f c o$, fin core; $h$, heart; Ih, lymphatic heart; Iv, liver diverticulum; $n$, notochord; nc, neural crest; np, neural plate; ns, nasal placode; ov, otic vesicle; $p$, pharynx; pt, pronephric tubules; s, somites; sp, spinal cord; vf, ventral fin.

and the duct of Cuvier and also in the heart (Fig. 6Aiii). At stage 41, enpp1 remains strongly expressed in the vasculature of the embryos, as seen in the tail (Fig. 6Aiv) and also its transcripts can be detected in the pronephric sinus (Fig. 6Av).

enpp4 is strongly expressed before MBT in the blastomeres of the animal pole of the embryos (Fig. 6Bi). Its zygotic expression is first detected in the cement gland from stage 16. The expression in this tissue is maintained until stage 38 (Fig. 6Bii-iv). From stage 22 until stage 28 , staining can be observed in the hatching gland, as shown on Fig. 6Bii. From stage 32, enpp4 is expressed in the developing pronephros and becomes strongly expressed in the proximal tubules (Fig. 6Biii,iv, section 6Bvi) although weaker expression can also be detected in the intermediate, distal and collecting tubules (Fig. 6Biv). Expression in the kidney remains detectable until stage 41, the last stage tested in this experiment (Fig. 6Bv). From tailbud stages, enpp4 is also expressed in the somites (Fig. 6Biii-v).
The enpp6 gene displays a very specific expression domain. Prior to MBT, enpp6 is expressed in the animal pole (Fig. 6Ci). After MBT, no staining can be observed until late tailbud stages. At stage 28, enpp6 is expressed in the brain and at a lower level in the developing pronephros (Fig. 6Cii). The level of expression in the kidney increases and at stage $37 / 38$, enpp6 is highly and specifically expressed in the pronephric proximal tubules (Fig. 6 Ciii,iv) where it remains expressed until stage 41 , the last stage tested.

enpp7 displays the most tissue restricted expression domain. As expected from its temporal expression profile, enpp 7 is only detected from stage 43 by in situ hybridisation. At stage 45, enpp 7 is highly and specifically expressed in the gut (Fig. 6Di,iii), in the external coil 3 and 4 of the small intestine (Fig. 6Div) whereas no expression of enpp7 can be observed in the anterior (sia) and the internal coil of the small intestine (sic) (Fig. 6Div). No staining in the gut region can be seen with the sense probe (Fig. 6Dii) 
The pseudoalleles enpp2a and enpp2b display different staining expression patterns. Both genes are expressed strongly in the animal pole of the embryo at stage 5 and 8 (Fig. 7Ai,ii). enpp2b is expressed in the developing neural plate from stage 15, whereas expression of enpp2a can not be detected before the end of neurulation. However, at stage 21 , enpp2a is expressed in the somites, in sensory placodes and neural crest (Fig. 7Aiii). enpp2b is also expressed in the somites and in the anterior nervous system (Fig. 7Aiv). Expression can also be observed in the developing eyes after clearing the embryos (data not shown). At tailbud stages, enpp2a expression is mainly detected in developing dorsal fin whereas enpp2b displays a broader expression pattern with strong staining detected in the eye, otic vesicle, branchial arches, somites, in the dorsal fin and in the pronephric tubules (Fig. 7Av,vi). Weaker expression of enpp2a can also be detected in the nervous system, pronephros and cement gland (Fig. 7Av). At stage 32, staining in the nervous system can be detected for both genes (Fig. 7B): enpp2a and enpp2b are both expressed in small populations of cells in the ventral part of the spinal cord (Fig. 7B ii,iii,v,vi) whereas enpp2b seems more expressed in the central nervous system than enpp2a (Fig. $7 \mathrm{Bi}, \mathrm{iv}$ ). From stage 32 to stage 41 , enpp2a remains strongly expressed in the dorsal and ventral fins (Fig. 7Avii, ix), in the fin core, composed of extracellular matrix and neural crest cells, but not in the fin crest which is a single epithelial layer as shown by transversal section (Tucker and Slack, 2004)(Fig. 7Ci). Expression in otic vesicle, branchial arches and somites can also be observed from these stages. At tadpole stages, enpp2b remains expressed in all tissues detected at earlier stages. Moreover, expression in the heart and in the liver diverticulum can be observed at stage 37/38 (Fig. 7Aviii). At stage 41, both enpp2a and enpp $2 b$ are expressed in several placodes, including the olfactory placodes (data not shown). enpp2a, but not enpp2b, can be detected in the lymphatic hearts (Fig. 7Cii).

\section{Discussion}

This paper reports the cloning of 6 members of the enpp gene family in Xenopus and their expression during development and in adult frog tissues. Although this family has been intensively studied during the last few years, there is little data regarding the expression of these genes during development, except for ENPP2, autotaxin (Bächner et al., 1999; Ohuchi et al., 2007). Our work is the first to comprehensively compare the expression pattern of all enpp genes during the development of any vertebrate and also to compare embryonic expression patterns with those in adult tissues.

\section{Evolutionary conserved members of the enpp family are present in Xenopus}

Our study reveals that all members of the enpp family, except enpp5, are present in $X$. laevis and tropicalis. We failed to amplify any enpp5 sequences, suggesting that there may be no enpp5 ortholog in either Xenopus species. Phylogenetic analysis demonstrates that the enpp family is highly conserved between frog species and also during vertebrate evolution both at the protein level and at the level of genomic organisation. Indeed, BLAST analyses demonstrate that enpp1 and enpp3 genomic sequences are located on the same scaffold (scaffold 200) in $X$. tropicalis.
This linkage (or synteny) is conserved in other vertebrate species such as human, mouse, chimpanzee and cows, suggesting that enpp1 and enpp3 might originate by duplication of an ancestral gene, this duplication having taken place before the emergence of amphibia. This is consistent with the fact that in protein sequence, enpp1 is more related to enpp3 than to its enpp2 homolog.

\section{Two enpp2 genes in Xenopus laevis}

During this work, we isolated two genes encoding enpp2 in $X$. laevis, named enpp2a and enpp2b. These two sequences must correspond to the two pseudo-allelic enpp2 sequences since they both identify by BLAST the same $X$. tropicalis genomic sequences. Moreover, these two genes display different expression patterns during development which suggests that these two sequences have been retained in $X$. laevis due to spatial subfunctionalization. Studies based on full length cDNA clone analysis have demonstrated that approximately $14 \%$ of paralogous pairs in $X$. laevis show differential expression patterns indicative of sub-functionalization (Morin et al., 2006). Recently, we demonstrated by in situ hybridisation that this was indeed the case for the 2 pseudo-alleles coding for Annexin 4 (Massé et al., 2007). In mammalian species, several transcripts encoding ENPP2, which result from alternative splicing, have been identified. They display different expression patterns (van Meeteren and Moolenaar, 2007; Giganti et al., 2008), although the physiological relevance for these different isoforms is still unknown.

Based on sequence analysis, it seems that enpp2a and enpp $2 b$ have duplicated from an ancestral gene and have evolved independently at an equal rate. However, based on expression patterns, we suggest that enpp2b is closer to the ancestral gene since the mouse ortholog of enpp $2 b$ has a similar expression pattern in the neural plate, somites and kidney (Bächner et al., 1999). It is worth noting that the enpp2 gene, described in Xenbase, corresponds to our enpp2b sequence whereas the sequence referred to as enpp2 on the NCBI website encodes the enpp2a protein.

EST analysis for the other enpp members indicates pseudoallelic sequences are present in $X$. laevis, but we have not investigated this any further. It might be interesting to analyse if their expression patterns diverge as enpp2a and enpp2b.

\section{The expression patterns of enpp genes are temporally and spatially regulated}

Although enpp1, 2a, $2 \mathrm{~b}$ and 3 are highly related in sequence, their expression patterns differ during development and in the adult frog, in both a temporal and spatial manner. The expression pattern of the enpp3 gene suggests a unique role for this family member during the early phase of development. The level of expression of the other enpp genes increases until stage 45, the last stage tested in this study. enpp4, enpp6 and enpp7 also display unique embryonic expression profiles. In the adult frog all tissues tested express more than one member of the enpp family. As in mammalian species, the enpp genes display distinct but overlapping expression profiles (Bollen et al., 2000; Sakagami et al., 2005; Duan et al., 2003). enpp7 displays the most tissue restricted expression pattern, being only detected in the adult intestine. All these genes are expressed maternally, except enpp7. Hydrolysis of lipids is critical for fertilization and LPC has 
been suggested to induce the membrane fusion needed for the sperm acrosomal reaction and sphingomeylin (SM) may play a role during membrane fusion and egg-sperm interactions by stabilizing rafts. SM and LPC levels decrease during fertilization, reflecting the activation of sphingomyelinase and lysoPLD enzymes such as the enpp proteins (Petcoff et al., 2008).

\section{Distinct expression patterns suggest specific roles during development}

We have shown that all enpp genes, except enpp5, are expressed during $X$. laevis development. The zygotic expression of enpp1, 2a, 2b, 3 is up-regulated during gastrula stages suggesting potential roles during early phases of development. However, their spatial expression profile seems to indicate distinct functions. During Xenopus embryogenesis, enpp 1 is highly expressed in blood compartments, and in the adult its ubiquitous expression may be due to expression in adult blood cells. In mammals, ENPP1 was first cloned as PC-1, a glycoprotein of mouse B-cells (Takahashi et al., 1970). The embryonic distribution of enpp1 in the ventral blood island in Xenopus-possibly reflects that production of $\mathrm{B}$-cell precursors which occurs in this region (Du Pasquier et al., 2000).

The functions of ENPP2 in cell proliferation, migration and survival are certainly linked to LPA production and to its lysoPLD activity (van Meeteren and Moolenaar, 2007) and not to the purine pathways, despite the fact that ATP is an inhibitor of tumour cell proliferation and adenosine a stimulator of angiogenesis (Stefan et al., 2006). Xenopus enpp2 genes are both expressed in embryonic and adult nervous systems and neural crest derivatives such as the fin, reflecting its importance during cell mobility. The expression in neural tissue is conserved during vertebrate evolution (Bächner et al., 1999; Ohuchi et al., 2007) suggesting that enpp2 is critical to both normal development and function of the nervous system. Human ENPP2 is involved in the secretion of cerebrospinal fluid, differentiation of oligodendrocytes but also in pathological conditions such as multiple sclerosis, neuropathic pain and Alzheimer-type dementia (ATD) (reviewed in Yuelling and Fuss, 2008; Dennis et al., 2005) Despite the importance of purine signalling in the nervous system, it seems that these neuronal functions are likely to be mediated by a novel domain located in the ENPP2 C-terminal region, the MORFO domain (Yuelling and Fuss, 2008). Mouse knock-outs for Enpp2 are embryonic lethal and therefore uninformative (Tanaka et al., 2006; van Meeteren et al., 2006)

In Xenopus embryogenesis, enpp3 is strongly expressed during neurulation. Moreover, in the adult, enpp3 transcripts can be detected in almost every tissue tested but are at a higher level in lung, kidney, intestine tract and skin. This expression profile reflects the importance of purinergic signalling in the extracellular environment of epithelial cells (reviewed in Schwieber and Zsembery, 2003) mammalian enpp3 having been shown to be involved in airway, liver and intestinal epithelial functions (Stefan et al., 2006)

The enpp4-7 members are all expressed later in development, during organogenesis. enpp4 expression level increases at late neurulation and the zygotic expression of enpp6 and 7 can only be detected at late swimming tadpole stages, ruling out any role for these 2 proteins during early developmental processes. The pronephric expression of enpp6 is upregulated when the pronephros becomes fully formed and functional (Vize, 2003) suggesting a role in the differentiated function of this organ. enpp7 is highly expressed in the gut at the start of independent feeding, when the tadpole gut has acquired its coiled structure and is fully functional (Chalmers and Slack, 1998). Therefore, we could speculate that these two enpp gene family members might be more involved in the physiological function of these organs as has been suggested in humans. ENPP7 hydrolyses sphingomyelin (SM) in the intestinal tract and therefore plays anti-proliferative and anti-inflammatory roles by generating ceramide and also can affect cholesterol uptake (reviewed in Duan, 2006). ENPP6 might be involved in the resorption of choline by degrading cholinecontaining compounds such as LPC and SPC but also may have a role in the kidney by producing bioactive lipids such as arachidonoylglycerol and sphingosine (Sakagami et al., 2008).

\section{Several enpp family members play a conserved role in verte- brate kidney development/function}

Several enpp family genes are highly expressed in the pronephros but also in the adult kidney, the mesonephros. enpp2b is transiently expressed in the tubules during tailbud stages. In the mouse, Enpp2 is also expressed in the embryonic kidney (Bächner et al., 1999). Our work is the first study to describe a strong and specific expression during pronephric development of enpp4. In mammals, no data are available concerning the expression of this gene. In the adult frog, enpp4 is also expressed in the kidney, but as in human, its expression in the adult tissues appears to be ubiquitous (data from Unigene Hs709868). enpp6 displays the strongest expression in the kidney. Unlike enpp2b and enpp4, this member is only expressed in the proximal tubules. This is in agreement with the expression of its human ortholog, found only in the proximal tubules and thin descending limbs of Henle (Sakagami et al., 2005). This specific and strong expression in the kidney is also seen in the adult frog, emphasising the important roles that enpp6 could play in kidney physiology in vertebrates. enpp3 is also expressed strongly in the adult kidney and enpp1 and enpp $2 b$ transcripts can also be detected at low levels in this organ. Therefore, the kidney appears to be a major site of expression for the enpp gene family. In human, each enpp gene, except enpp7, is expressed in the adult metanephros (Bollen et al., 2000; Sakagami et al., 2005). This is consistent with the expression in that organ of LPA2, LPA4 and S1P1-4, bioactive lipid receptors (Contos et al., 2000; Awad et al., 2006) and also with the importance of the purinoreceptors (reviewed in Unwin et al., 2003), whose misexpression has been implicated in polycystic kidney disease (Turner et al., 2004). Purinergic signalling plays essential roles in both normal renal physiology and pathological renal cases (reviewed in Hovater et al., 2008).

\section{Xenopus is an appropriate model to study enpp gene func- tion}

There is a high degree of conservation of expression profile of this family between frogs and higher vertebrates. For example, enpp7 is only expressed in the frog small intestine, which is consistent with the mammalian gene expression (Duan et al., 2003) and enpp6 transcripts are preferentially detected in the kidney, as its human ortholog (Sakagami et al., 2005). Therefore, we suggest that their functions will also be similar. We have recently shown that ectonucleotidases of the E-NTPDase family 
are expressed in a developmentally regulated manner, and one member of this family, E-NTPDase2, is responsible for triggering eye development via its effects on purinergic signalling (Massé et al., 2006, 2007). This previously published work illustrates that the power of the amphibian $X$. laevis to establish previously unknown developmental signalling pathways during development. Functional analysis of the enpp genes family during kidney formation, one of the major sites of their expression, is now in process in the laboratory, using a combination of morpholino knock-down and over-expression strategies.

\section{Material and Methods}

\section{Bioinformatics}

$X$. laevis and $X$. tropicalis EST clones were identified by a TBLASTN (Basic Local Alignment Search Tool) search on the NCBI EST others databases using the sequence from the orthologous human proteins (Altschul et al., 1990). Genomic X. tropicalis sequences were identified by the same search on the Joint Genome Institute (JGI) website (http:// genome.jgi-psf.org/Xentr4/Xentr4.home.html). Accession numbers of all sequences used in this study are given in Supplementary Table 1B. Pairwise alignments were performed using the Needle program based on Needleman-Wunsch global alignment algorithm (European Bioinformatics Institute website) (Needleman and Wunsch, 1970). Multiple alignment was performed using the software CLUSTALW (Thompson et al., 1994). For phylogeny studies, catalytic domain sequences were aligned using the GeneBee algorithm and a phylogenetic tree produced using the PHYLIP program (Brodsky et al., 1992) Conceptual translation of cDNA and protein sequence analysis was performed on the ExPaSy website http://www.expasy.org/tools/\#ptm).

\section{DNA}

The identified I.M.A.G.E clones were ordered from the Geneservice Ltd Cambridge (Supplementary Table 1B). DNA was extracted from several individual colonies, verified by restriction analysis and sequenced from both strands. When required, primers were designed to complete the sequencing of each clone.

\section{Embryo culture and dissections}

Culture of the embryos was performed as described previously (Massé et al., 2004). The embryos were staged according to Nieuwkoop and Faber, 1994.

\section{RT-PCR}

RNA extraction from embryonic and adult tissues and cDNA synthesis were performed as described by Barnett et al., 1998. For each gene, specific primers were designed based on the $X$. laevis sequences (Supplementary Table 2). Each PCR was optimised and verified by sequencing as described previously. PCR was then carried out with nonradioactive nucleotides according to details in Supplementary Table 2. For each experiment, the quantity of input CDNA was determined by equalisation of the samples with a constant gene, either $O D C$ or $E f 1 \alpha$. Linearity of signal was controlled by carrying out PCR reactions on doubling dilutions of cDNA, illustrated by the triangle. Negative controls were performed as indicated.

\section{Whole-mount in situ hybridisation}

Whole-mount in situ hybridisation was performed essentially as described in Harland, 1991 with several modifications. In order to minimise the cross-reactions between homologs, specific probes were designed in the 3'UTR of each gene. However, since $X$. laevis enpp1, enpp3 and enpp7 UTR sequences are not available, templates from the coding region of these genes were used to generate the antisense probes. In each case, sense probes were used to control the specificity of the staining. Details of the probes are documented in Supplementary Table 3. Each probe was made using a DIG RNA labelling kit (Roche) and the original DNA template was carefully removed after incubation with DNasel. Several washes in MAB buffer $(0.1 \mathrm{M}$ Maleic Acid, $0.15 \mathrm{M} \mathrm{NaCl})$ were performed following hybridisation of the probe. Hybridised probes were detected with a pre-absorbed anti DIG alkaline phosphatase-labelled antibody. The coloration reaction was performed with BM-Purple (Roche).

\section{Embedding and sectioning}

After whole-mount in situ hybridisation, enpp7 stained embryos were embedded in acrylamide as described by Seville et al., 2002. The blocks were sectioned on a microtome at $28 \mu \mathrm{m}$ thickness. Transverse sections were also performed with a razor blade on fixed embryos.

\section{Acknowledgments}

We thank $P$. Jarrett for the maintenance of the breeding frogs and $R$. Eason for technical help. This work was supported by the Wellcome Trust, Grant no 082071.

\section{References}

ALTSCHUL SF, GISH W, MILLER W, MYERS EW, LIPMAN DJ (1990) Basic local alignment search tool. J Mol Biol 215: 403-410.

ANDOH A, PIAO JH, TERASHIMA K, NAKAMURA H, SANO K (1999) Genomic structure and promoter analysis of the ecto-phosphodiesterase I gene (PDNP3) expressed in glial cells. Biochim Biophys Acta 1446: 213-224.

AWAD AS, YE H, HUANG L, LI L, FOSS FW JR, MACDONALD TL, LYNCH KR, OKUSA MD (2006) Selective sphingosine 1-phosphate 1 receptor activation reduces ischemia-reperfusion injury in mouse kidney. Am J Physiol Renal Physiol 290: F1516-F1524.

BÄCHNER S, AHRENS, M, BETAT N, SCHRDER D, GROSS G (1999) Developmental expression analysis of murine autotaxin (ATX). Mech Dev 84: 121-125.

BARNETT MW, OLD RW, JONES EA (1998) Neural induction and patterning by fibroblast growth factor, notochord and somite tissue in Xenopus. Dev Growth Differ 40: 47-57.

BOLLEN M, GIJSBERS R, CEULEMANS H, STALMANS W, STEFAN C (2000) Nucleotide pyrophosphatases/phosphodiesterases on the move. Crit Rev Biochem Mol Biol 35: 393-432.

BREATHNACH R, CHAMBON P (1981) Organization and expression of eucaryotic split genes coding for proteins. Annu Rev Biochem 50: 349-383.

BRODSKY, L., VASILYEV, A., KALAYDZIDIS, Y., OSIPOV, Y., TATUZOV, A. and FERANCHUK, S. (1992) GeneBee: the Program Package for Biopolymer Structure Analysis. Dimacs 8: 127-139.

BÜHRING HJ, SIMMONS PJ, PUDNEY M, MÜLLER R, JARROSSAY D, VAN AGTHOVEN A, WILLHEIM M, BRUGGER W, VALENT P, KANZ L (1999) The monoclonal antibody $97 A 6$ defines a novel surface antigen expressed on human basophils and their multipotent and unipotent progenitors. Blood 94: 2343-2356.

BÜHRING HJ, SEIFFERT M, GIESERT C, MARXER A, KANZ L, VALENT P, SANO $\mathrm{K}(2001)$ The basophil activation marker defined by antibody $97 \mathrm{~A} 6$ is identical to the ectonucleotide pyrophosphatase/phosphodiesterase 3. Blood 97: 33033305.

BÜHRING HJ, STREBLE A, VALENT P (2004) The basophil-specific ectoenzyme E-NPP3 (CD203c) as a marker for cell activation and allergy diagnosis. Int Arch Allergy Immunol 133: 317-329.

CHALMERS AD, SLACKJW (1998) Development of the gut in Xenopus laevis. Dev Dyn 212: 509-521.

CIMPEAN A, STEFAN C, GIJSBERS R, STALMANS W, BOLLEN M (2004) Substrate-specifying determinants of the nucleotide pyrophosphatases/phosphodiesterases NPP1 and NPP2. Biochem J 38: 71-77.

CONTOS JJ, ISHII I, CHUN I (2000) Lysophosphatidic acid receptors. Mol Pharmacol 58: 1188-1196.

DEISSLER H, LOTTSPEICH F, RAJEWSKY MF (1995) Affinity purification and CDNA cloning of rat neural differentiation and tumor cell surface antigen gp130RB13-6 reveals relationship to human and murine PC-1. J Biol Chem 
270: 9849-9855.

DENNIS J, NOGAROLI L, FUSS B (2005) Phosphodiesterase-lalpha/autotaxin (PD-lalpha/ATX): a multifunctional protein involved in central nervous system development and disease. J Neurosci Res 82: 737-742.

DU PASQUIER L, ROBERT J, COURTET M, MUSSMANN R (2000) B-cell development in the amphibian Xenopus. Immunol Rev 175: 201-213.

DUAN RD (2006) Alkaline sphingomyelinase: An old enzyme with novel implications. Bioc1761 Biochim Biophys Acta 1761: 281-291.

DUAN RD, BERGMAN T, XU N, WU J, CHENG Y, DUAN J, NELANDER S PALMBERG C, NILSSON A (2003) Identification of human intestinal alkaline sphingomyelinase as a novel ecto-enzyme related to the nucleotide phosphodiesterase family. J Biol Chem 278: 38528-38536.

FERRY G, GIGANTI A, COG F, BERTAUX F, THIAM K, BOUTIN JA (2007) Functional invalidation of the autotaxin gene by a single amino acid mutation in mouse is lethal. FEBS Lett 581: 3572-3578.

GIGANTI A, RODRIGUEZ M, FOULD B, MOULHARAT N, COGÉ F, CHOMARAT P, GALIZZI JP, VALET P, SAULNIER-BLACHE JS, BOUTIN JA, FERRY G (2008) Murine and human autotaxin alpha, beta, and gamma isoforms: gene organization, tissue distribution, and biochemical characterization. J Biol Chem 283: 7776-7789.

GIJSBERSR, AOKIJ, ARAIH, BOLLEN M (2003) The hydrolysis of lysophospholipids and nucleotides by autotaxin (NPP2) involves a single catalytic site. FEBS Lett 538: $60-64$.

GIJSBERS R, CEULEMANS H, STALMANS W, BOLLEN M (2001) Structural and catalytic similarities between nucleotide pyrophosphatases/phosphodiesterases and alkaline phosphatases. J Biol Chem 276: 1361-1368.

GODING JW, GROBBEN B, SLEGERS H (2003) Physiological and pathophysiological functions of the ecto-nucleotide pyrophosphatase/phosphodiesterase family. Biochim Biophys Acta. 1638: 1-19.

GROBBEN B, CLAES P, ROYMANS D, ESMANS EL, VAN ONCKELEN H, SLEGERS H (2000) Ecto-nucleotide pyrophosphatase modulates the purinoceptor-mediated signal transduction and is inhibited by purinoceptor antagonists. Br J Pharmacol 130:139-145

HARLAND RM (1991) In situ hybridization: an improved whole-mount method for Xenopus embryos. Methods Cell Biol 36: 685-695

HOVATER MB, OLTEANU D, WELTY EA, SCHWIEBERT EM (2008) Purinergic signaling in the lumen of a normal nephron and in remodeled PKD encapsulated cysts. Purinergic Signal 4: 109-124.

JANSEN S, STEFAN C, CREEMERS JW, WAELKENS E, VAN EYNDE A, STALMANS W, BOLLEN M (2005) Proteolytic maturation and activation of autotaxin (NPP2), a secreted metastasis-enhancing lysophospholipase D. $J$ Cell Sci 118: 3081-3089.

JIN-HUA P, GODING JW, NAKAMURA H, SANO K (1997) Molecular cloning and chromosomal localization of PD-Ibeta (PDNP3), a new member of the human phosphodiesterase I genes. Genomics 45: 412-415.

KAWAGOE $H$, SOMA O, GOJI J, NISHIMURA N, NARITA M, INAZAWA J, NAKAMURA H, and SANO, K. (1995). Molecular cloning and chromosomal assignment of the human brain-type phosphodiesterase I/nucleotide pyrophosphatase gene (PDNP2). Genomics 30: 380-384.

LAZAROWSKI ER, BOUCHER RC, HARDEN TK (2000) Constitutive release of ATP and evidence for major contribution of ecto-nucleotide pyrophosphatase and nucleoside diphosphokinase to extracellular nucleotide concentrations. $J$ Biol Chem 275: 31061-31068.

LEE J, JUNG ID, NAM SW, CLAIR T, JEONG EM, HONG SY, HAN JW, LEE HW, STRACKE ML, LEE HY (2001)Enzymatic activation of autotaxin by divalent cations without EF-hand loop region involvement. Biochem Pharmacol62: 219 224.

MADDUX BA, GOLDFINE ID (2000) Membrane glycoprotein PC-1 inhibition of insulin receptor function occurs via direct interaction with the receptor alphasubunit. Diabetes 49: 13-19.

MASSÉ K, BALDWIN R, BARNETT MW, JONES EA (2004) X-epilectin:a novel epidermal fucolectins regulated by BMP signalling. Int J Dev Bio/48: 1119-1129.

MASSÉ K, EASON R, BAMHRA S, DALE N, JONES EA (2006) Comparative genomic and expression analysis of the conserved NTPDase gene family in Xenopus. Genomics 87: 366-381.

MASSÉ K, BAMHRA S, EASON R, DALE N, JONES EA (2007a) Purine-mediated signalling triggers eye development. Nature 449:1058-1062.

MASSÉ K, COLLINS R, BHAMRA S, SEVILLE R, JONES EA (2007b) Anx4 genes are expressed in distinct organ systems in Xenopus laevis and tropicalis but are functionally conserved. Organogenesis 3: 83-92.

MEYRE D, BOUATIA-NAJI N, TOUNIAN A, SAMSON C, LECOEUR C, VATIN V GHOUSSAINI M, WACHTER C, HERCBERG S, CHARPENTIER G, PATSCH W, PATTOU F, CHARLES MA, TOUNIAN P, CLÉMENT K, JOURET B, WEILL J, MADDUX BA, GOLDFINE ID, WALLEY A, BOUTIN P, DINA C, FROGUEL P (2005) Variants of ENPP1 are associated with childhood and adult obesity and increase the risk of glucose intolerance and type 2 diabetes. Nat Genet 37: 863 867.

MORIN RD, CHANG E, PETRESCU A, LIAO N, GRIFFITH M, CHOW W KIRKPATRICK R, BUTTERFIELD YS, YOUNG AC, STOTT J, BARBER S, BABAKAIFF R, DICKSON MC, MATSUO C, WONG D, YANG GS, SMAILUS DE, WETHERBY KD, KWONG PN, GRIMWOOD J, BRINKLEY CP 3RD, BROWN-JOHN M, REDDIX-DUGUE ND, MAYO M, SCHMUTZ J, BELAND J, PARK M, GIBSON S, OLSON T, BOUFFARD GG, TSAI M, FEATHERSTONE R, CHAND S, SIDDIQUI AS, JANG W, LEE E, KLEIN SL, BLAKESLEY RW, ZEEBERG BR, NARASIMHAN S, WEINSTEIN JN, PENNACCHIO CP, MYERS RM, GREEN ED, WAGNER L, GERHARD DS, MARRA MA, JONES SJ, HOLT RA (2006). Sequencing and analysis of 10,967 full-length cDNA clones from Xenopus laevis and Xenopus tropicalis reveals post-tetraploidization transcriptome remodeling. Genome Res 16: 796-803.

MURATA J, LEE HY, CLAIR T, KRUTZSCH HC, ARESTAD AA, SOBEL ME, LIOTTA LA, STRACKE ML (1994) CDNA cloning of the human tumor motilitystimulating protein, autotaxin, reveals a homology with phosphodiesterases. $J$ Biol Chem 269: 30479-30484.

NAKAMURA I, IKEGAWA S, OKAWA A, OKUDA S, KOSHIZUKA Y, KAWAGUCH $\mathrm{H}$, NAKAMURA K, KOYAMA T, GOTO S, TOGUCHIDA J, MATSUSHITA M, OCHI T, TAKAOKA K, NAKAMURA Y (1999) Association of the human NPPS gene with ossification of the posterior longitudinal ligament of the spine (OPLL). Hum Genet 104: 492-497.

NARITA M, GOJI J, NAKAMURA H, SANO K (1964) Molecular cloning, expression, and localization of a brain-specific phosphodiesterase I/nucleotide pyrophosphatase (PD-I alpha) from rat brain. J Biol Chem 269: 28235-28242.

NEEDLEMAN SB, WUNSCH CD (1970) A general method applicable to the search for similarities in the amino acid sequence of two proteins. J Mol Biol 48: 443 453.

NIEUWKOOP PD, FABER J (1994) Normal table of Xenopus laevis (Daudin). Garland Publishing, Inc. New York.

OHUCHI H, HAYASHIBARA Y, MATSUDA H, ONOI M, MITSUMORI M, TANAKA M, AOKI J, ARAI H, NOJI S (2007) Diversified expression patterns of autotaxin, a gene for phospholipid-generating enzyme during mouse and chicken development. Dev Dyn 236: 1134-1143.

OKAWA A, NAKAMURA I, GOTO S, MORIYA H, NAKAMURA Y, IKEGAWA S (1998) Mutation in Npps in a mouse model of ossification of the posterior longitudinal ligament of the spine. Nat Genet 19: 271-273.

PETCOFF DW, HOLLAND WL, STITH BJ (2008) Lipid levels in sperm, eggs, and during fertilization in Xenopus laevis. J Lipid Res 49: 2365-23678

REBBE NF, TONG BD, FINLEY EM, HICKMAN S (1991) Identification of nucleotide pyrophosphatase/alkaline phosphodiesterase I activity associated with the mouse plasma cell differentiation antigen PC-1. Proc Natl Acad Sci USA. 88 5192-5196.

RUTSCH F, RUF N, VAINGANKAR S, TOLIAT MR, SUK A, HÖHNE W, SCHAUER G, LEHMANN M, ROSCIOLI T, SCHNABEL D, EPPLEN JT, KNISELY A SUPERTI-FURGA A, MCGILL J, FILIPPONE M, SINAIKO AR, VALLANCE H, HINRICHS B, SMITH W, FERRE M, TERKELTAUB R, NÜRNBERG P (2003) Mutations in ENPP1 are associated with 'idiopathic' infantile arterial calcification. Nat Genet 34: 379-381.

SAKAGAMI H, AOKI J, NATORI Y, NISHIKAWA K, KAKEHI Y, NATORI Y, ARAI H (2005) Biochemical and molecular characterization of a novel choline-specific glycerophosphodiester phosphodiesterase belonging to the nucleotide pyrophosphatase/phosphodiesterase family. J Biol Chem 280: 23084-23093.

SCHWIEBERT EM, ZSEMBERY A (2003) Extracellular ATP as a signaling molecule for epithelial cells. Biochim Biophys Acta 1615: 7-32.

SCOTT LJ, DELAUTIER D, MEERSON NR, TRUGNAN G, GODING JW, MAURICE $M(1997)$ Biochemical and molecular identification of distinct forms of alkaline 
phosphodiesterase I expressed on the apical and basolateral plasma membrane surfaces of rat hepatocytes. Hepatology 25: 995-1002.

SEVILLE RA, NIJJAR S, BARNETT MW, MASS K, JONES EA (2002) Annexin IV $(\mathrm{Xanx}-4)$ has a functional role in the formation of pronephric tubules. Development 129: 693-704.

STEFAN C, JANSEN S, BOLLEN M (2005) NPP-type ectophosphodiesterases: unity in diversity. Trends Biochem Sci 30: 542-550.

STEFAN C, JANSEN S, BOLLEN M (2006) Modulation of purinergic signaling by NPP-type ectophosphodiesterases. Purinergic Signal 2: 361-370.

STRACKE ML, KRUTZSCH HC, UNSWORTH EJ, ARESTAD A, CIOCE V, SCHIFFMANN E, and LIOTTA, L.A. (1992) Identification, purification, and partial sequence analysis of autotaxin, a novel motility-stimulating protein. J Biol Chem 267: 2524-2529.

TAKAHASHI T, OLD LJ, BOYSE EA (1970) Surface alloantigens of plasma cells. $J$ Exp Med 131: 1325-1341.

TANAKA M, OKUDAIRA S, KISHI Y, OHKAWA R, ISEKI S, OTA M, NOJI S, YATOMI Y, AOKI J, ARAI H (2006) Autotaxin stabilizes blood vessels and is required for embryonic vasculature by producing lysophosphatidic acid. J Biol Chem 281: 25822-25830.

TERKELTAUB R (2006) Physiologic and pathologic functions of the NPP nucleotide pyrophosphatase/phosphodiesterase family focusing on NPP1 in calcification. Purinergic Signal 2: 371-377.

THOMPSON JD, HIGGINS DG, GIBSON TJ (1994) CLUSTALW: improving the sensitivity of progressive multiple sequence alignment through sequences weighting, position-specific gap penalties and weight matrix choice. Nucleic Acids Research 22: 4673-4680.

TOKUMURA A, MAJIMA E, KARIYA Y, TOMINAGA K, KOGURE K, YASUDA K, FUKUZAWA K (2002) Identification of human plasma lysophospholipase D, a lysophosphatidic acid-producing enzyme, as autotaxin, a multifunctional phosphodiesterase. J Biol Chem 277: 39436-39442.

TUCKER AS, SLACK JM (2004) Independent induction and formation of the dorsal and ventral fins in Xenopus laevis. Dev Dyn 230: 461-467.
TURNER CM, RAMESH B, SRAI SK, BURNSTOCK G, UNWIN RJ (2004) Altered ATP-sensitive P2 receptor subtype expression in the Han:SPRD cy/+ rat, a model of autosomal dominant polycystic kidney disease. Cells Tissues Organs 178: $168-179$

UMEZU-GOTO M, KISHI Y, TAIRA A, HAMA K, DOHMAE N, TAKIO K, YAMORI T, MILLS GB, INOUE K, AOKI J, ARAI H (2002) Autotaxin has lysophospholipase D activity leading to tumor cell growth and motility by lysophosphatidic acid production. J Cell Biol 158: 227-233.

UNWIN RJ, BAILEY MA, BURNSTOCK G (2003) Purinergic signaling along the renal tubule: the current state of play. News Physiol Sci 18: 237-241.

VAN MEETEREN LA, MOOLENAAR WH (2007) Regulation and biological activities of the autotaxin-LPA axis. Prog Lipid Res 46: 145-160.

VAN MEETEREN LA, RUURS P, STORTELERS C, BOUWMAN P, VAN ROOIJEN MA, PRADÈRE JP, PETTIT TR, WAKELAM MJ, SAULNIER-BLACHE JS, MUMMERY CL, MOOLENAAR WH, JONKERS J (2006) Autotaxin, a secreted lysophospholipase $\mathrm{D}$, is essential for blood vessel formation during development. Mol Cell Biol 26: 5015-5022.

VIZE PD (2003) Induction, Development and Physiology of the pronephric tubules in The kidney: From normal development to congenital disease Elsevier Science, Academic Press, London, pp. 19-50.

WU J, LIU F, NILSSON A, DUAN RD (2004) Pancreatic trypsin cleaves intestinal alkaline sphingomyelinase from mucosa and enhances the sphingomyelinase activity.Am J Physiol Gastrointest Liver Physiol 287: G967-G973.

YUELLING LM, FUSS B (2008) Autotaxin (ATX): A multi-functional and multimodular protein possessing enzymatic lysoPLD activity and matricellular properties. Biochim Biophys Acta 1781: 525-530.

ZIMMERMANN H (1999) Two novel families of ectonucleotidases: molecular structures, catalytic properties and a search for function. Trends Pharmacol Sci 20: $231-236$.

ZIMMERMANN H (2001) Ectonucleotidases: Some recent developments and a note on nomenclature. Drug Dev Res 52: 44-56.

\section{Further Related Reading, published previously in the Int. J. Dev. Biol.}

See our recent Special Issue Epigenetics \& Development edited by Saadi Khochbin and Stefan Nonchev at: http://www.ijdb.ehu.es/web/contents.php?vol=53\&issue=2-3

\section{Cadherin-6 is required for zebrafish nephrogenesis during early development} Fumitaka Kubota, Tohru Murakami, Kenji Mogi and Hiroshi Yorifuji Int. J. Dev. Biol. (2007) 51: 123-129

The role of XTRAP-gamma in Xenopus pronephros development Dong-hui Li, Techuan Chan, Reiko Satow, Shinji Komazaki, Kouhei Hashizume and Makoto Asashima

Int. J. Dev. Biol. (2005) 49: 401-408

Developmental expression of Pod 1 in Xenopus laevis Subreena Simrick, Karine Massé and Elizabeth A. Jones Int. J. Dev. Biol. (2005) 49: 59-63

Isolation and growth factor inducibility of the Xenopus laevis Lmx1b gene. Caroline E Haldin, Sarjit Nijjar, Karine Massé, Mark W Barnett and Elizabeth A Jones Int. J. Dev. Biol. (2003) 47: 253-262

In vitro induction systems for analyses of amphibian organogenesis and body patterning. T Ariizumi and M Asashima Int. J. Dev. Biol. (2001) 45: 273-279
5 yr ISI Impact Factor $(2008)=3.271$

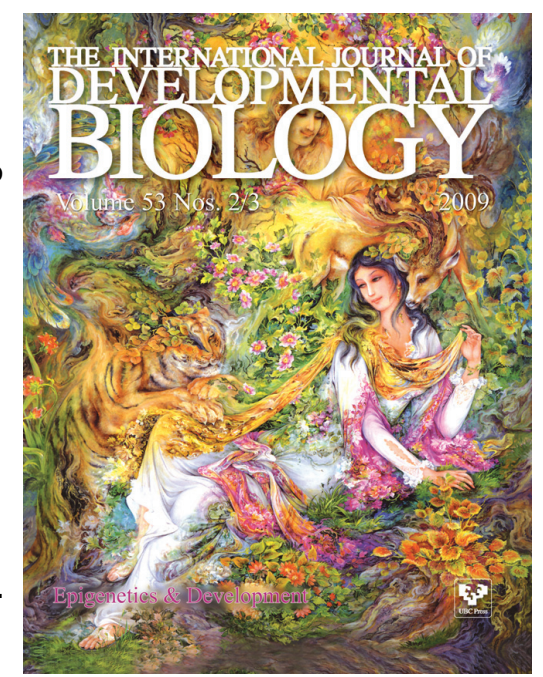

